\title{
TREATMENT OF RECURRENT TEMPOROMANDIBULAR JOINT DISLOCATION WITH BOTULINUM TOXIN \\ Shehata $\mathrm{B}^{1} B D S$, Darwish $\mathrm{S}^{2} P h D$, Aly $\mathrm{T}^{2} P h D$, Younis $\mathrm{G}^{3} P h D$.
}

\begin{abstract}
:
Introduction: The use of botulinum toxin type A (BTX-A) injection as it is a more recently reported treatment to alter the musculature with the intended effect to weaken the lateral pterygoid muscle (LPM) sufficiently to prevent temporomandibular joint (TMJ) dislocation. This caused a new imbalance between the muscles used for opening and closing the jaws, and mouth opening was slightly limited because of the weakness of the LPM.
\end{abstract}

Objectives: To evaluate the efficacy of injection of BTX-A as the first choice of treatment for patients with chronic TMJ dislocation not responding to conservative line of treatment.

Materials and methods: A prospective study was conducted on a total of 20 patients complaining of recurrent episodes of chronic TMJ dislocation. Group A: (The study group) patients were injected with BTX-A in the LPM through an intraoral approach, Group B: (The control group) patients suffering from chronic TMJ dislocation and treated by inter maxillary fixation (IMF).

Results: The study revealed that injecting BTX-A in the LPM prevents the TMJ dislocation and reduced pain caused by the movement of the LPM by $90 \%$ through temporary paralysis of the muscle, thus allowing the muscle to move more naturally.

Conclusions: This is a relatively conservative option, injection into the muscle is straightforward and can be done in outpatients with few complications.

Key words: Temporomandibular joint; Dislocation; Botulinum toxin type A; Lateral pterygoid muscle.

1- Master student at the Oral and Maxillofacial Surgery department, Faculty of Dentistry, Alexandria University.

2- Professor of Oral and Maxillofacial Surgery, Faculty of Dentistry, Alexandria University.

3- Professor of Physical Medicine, Rheumatology \& Rehabilitation, Faculty of Medicine, Alexandria University.

\section{INTRODUCTION}

Dislocation of the temporomandibular joint (TMJ) is defined as an excessive forward movement of the condyle beyond the articular eminence with complete separation of the articular surfaces and fixation in that position (1).

It is usually classified as acute, recurrent, or habitual. Acute is common and may be post-traumatic, spontaneous, or associated with psychiatric illness. When it becomes more frequent and progressively worse it is described as habitual or recurrent (2).

There are multiple causes for its occurrence, and treatments range from relatively conservative methods to complex surgical intervention (3), it represents $3 \%$ of all reported dislocated joints in the body (4).

Another classification based on relationship of the head of mandibular condyle to the articular eminence seen on clinico-radiological evaluation into three types (I-III) (5).

Type I: $\quad$ The head of condyle is directly below the tip of the eminence.

Type II: The head of condyle is in front of the tip of the eminence.

Type III: The head of condyle is high up in front of the base of eminence.

In 1832, Sir Astley Cooper proposed principles for diagnosis and treatment of dislocation of the lower jaw. He introduced the terms complete dislocation (luxation) and imperfect dislocation (subluxation), and other authors have further delineated the 2 conditions. Subluxation is generally defined as a displacement of the condyle out of the glenoid fossa and anterosuperior to the articular eminence, which can be reduced by the patient (self-reduced). Clinical and radiographic analysis have indicated that approximately $70 \%$ of the population can subluxate the TMJ. In contrast, dislocation is a similar displacement of the condyle, which cannot be self-reduced (6).

Some predisposing and etiological factors of TMJ dislocation include congenital joint weakness; extreme mouth opening during yawning; dental and otorhinolaryngological (ORL) treatment; trauma; drugs, especially the anti-emetics as metoclopramide and phenothiazines which produce extra pyramidal effects (Abnormal involuntary movements); hypermobility, associated with systemic diseases such as connective tissue disorders, Ehlers-Danlos syndrome; and psychogenic and neurological disorders (7).

Signs and symptoms of acute and chronic dislocation are the same and include: inability to close the mouth, preauricular depression of the skin, excessive salivation, tense, spasmatic muscles of mastication, and severe pain of the TMJ (8).

In all patients, the digital lateral double TMJ radiographs, open position, showed presence of both condyles anterior to the articular eminence in varying degrees(9).

The stability of any joint depends on 3 factors; the integrity of the ligaments associated with the joint, the activity of the musculature acting on the joint, and the bony architecture of the joint surfaces (10).So the treatments of recurrent dislocation may be organized according to the stability factors into; alteration of the ligaments, alteration of the associated musculature, and alteration of the bony anatomy (10). 
Also treatment can be divided to non-surgical (conservative) and surgical treatment. In literature, different surgical and nonsurgical techniques have been used for treating patients with chronic recurrent TMJ dislocation (9). Injection of BTX-A has been reported to have a good outcome, and in some patients one injection may be sufficient (11).

Botulinum toxin type A injection is invasive, but is a relatively conservative option because it is a safe and effective treatment for dystonia. It can be used as an initial approach because injection into the lateral pterygoid muscle (LPM) is straightforward and can be done in outpatients with few complications (12).

In this study, the efficacy of injection of BTX-A in treatment of TMJ dislocation was evaluated on basis of functional and electromyography (EMG) evaluation post injection of the BTX-A in the LPM in cases of dislocation in different age groups.

\section{MATERIALS AND METHODS}

Twenty patients suffering from chronic recurrent TMJ dislocation were selected from the Oral and Maxillofacial Surgery Department - Faculty of Dentistry, Alexandria University.

The twenty patients were divided equally into two groups

Group A: 10 patients were injected with BTX-A in the LPM through an intraoral approach as a study group.

Group B: 10 patients were treated by inter-maxillary fixation (IMF) for 3 weeks as a control group.

Informed written consents were given by the patients after informing them about the operation and the risks of the operation.

\section{Inclusion criteria}

- Age range of the patients between 20 \& 50 years.

- Patients suffering from recurrent episodes of unilateral or bilateral TMJ dislocation due to muscular hyperactivity who did not respond to conservative therapy and patients whom compliance to conservative therapy was not possible as mental retardation.

\section{Exclusion criteria}

- Patients having neurological conditions affecting the motor end plate such as myasthenia gravis.

- Patients under anticoagulant therapy.

- Pregnant and lactating women.

- Cases of pre-existing dysphagia.

- Patients on muscle relaxants or antibiotics of aminoglycoside type.

- Patients have systemic diseases that may interfere with the BTX-A injection.

- Patients with parafunctional habits as bruxism.

\section{Materials}

Botulinum Toxin type A (Botox®, Allergan, Westport Co.Mayo, Ireland) (Figure 1)

- Botox ${ }^{\circledR}$ is represented as a white powder in a transparent glass vial.
- The active substance is Botulinum toxin type A from Clostridium botulinum. Each vial contains 100 Allergan units of Botox ${ }^{\circledR}$.

- The other ingredients are $0.5 \mathrm{mg}$ of human albumin and $0.9 \mathrm{mg}$ of sodium chloride.

- The product must be dissolved in sterile sodium chloride $9 \mathrm{mg} / \mathrm{ml}(0.9 \%)$ solution for injection.

- Store in a refrigerator $\left(2^{\circ} \mathrm{C}-8^{\circ} \mathrm{C}\right)$, or store in a freezer (at or below $-5^{\circ} \mathrm{C}$ ).

- Immediate use of solution is recommended

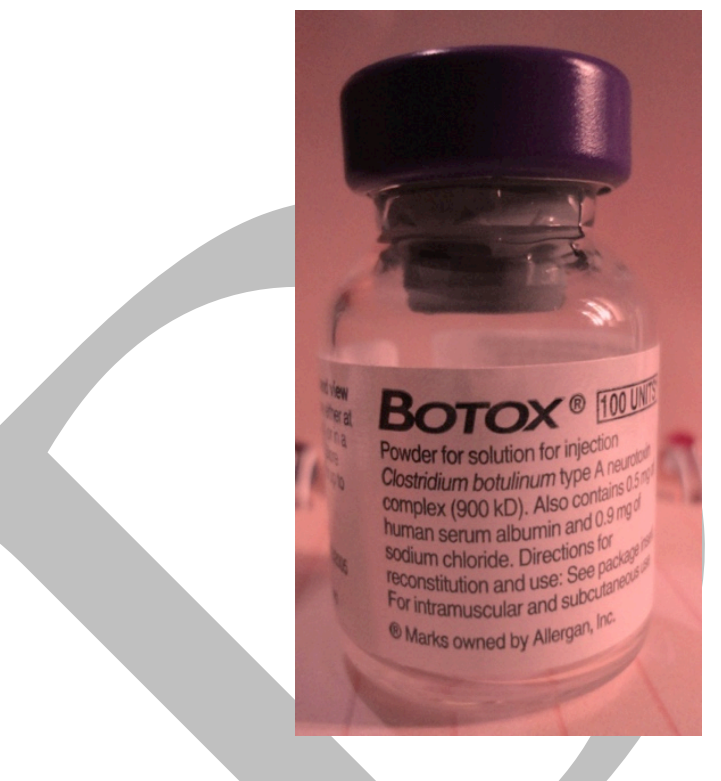

Fig. 1 A photograph showing the vial of the Botox ${ }^{\circledR}$.

Electromyography device (Nihon Kohden Corp., Tokyo, Japan) (Figure 2)

Electromyography is a device used to record the muscle's electrical activity. It is composed of:

\section{A screen}

It is used to show the muscle activity at rest state, and at functional state.

\section{Needle electrodes}

A special needle was used. The needle is composed of 27-gauge Teflon coated (lumen electrode 50 × $0.45 \mathrm{~mm}$ ) monopolar needle with dual action specifically engineered for Botox ${ }^{\circledR}$ injection and EMG study. It is coated with a low friction insulator for ease of insertion while allowing injection of the medication. It has a sharp point $(30 \%$ sharper than slip fit).

The needle hub is designed to allow for precise manipulation of the electrode. Injection Needle connects to standard disposable insulin syringes .The lead wire is flexible and permanently attached to the hub of the needle, so motion does not interfere with the injection process. The Injection Needle should be used with an EMG amplifier.

\section{Printer}

The device contains a printer to print out the report for each case. 


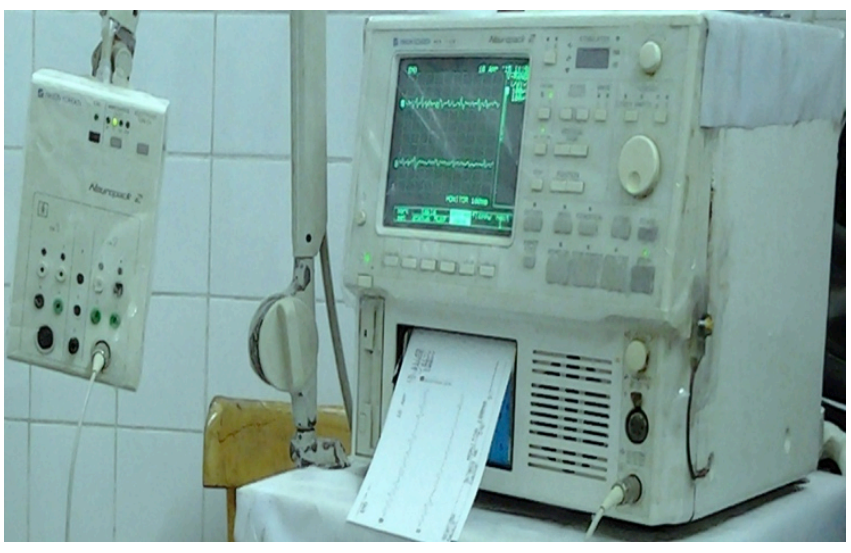

Fig. 2 A photograph showing the electromyography device.

\section{Methods}

\section{Pre-operative phase}

All cases were treated in outpatient clinic bases and were subjected to the following

\section{Clinical examination}

- Medical and dental history were obtained from each patient to evaluate their present and past medical and dental status. Previous medications and treatments were identified.

- Chief complaint and history of chief complaint; frequency of dislocation, pain duration, onset, relieving factors, and relation to other activities such as eating, talking and yawning.

- History of previous treatment measures.

- Habits such as nail biting or bruxism.

- Assessment of the interincisal distance by the mouth caliber.

- Assessment of the pain level of patients using the Visual Analogue Scale (VAS) from 0 (no pain) to 10 (most imaginable pain) before and after the treatment to measure reductions in pain intensity.

\section{A) Intra-oral examination}

- Examination of dentition and occlusion.

- Midline shift.

- Oral hygiene.

- Mouth opening.

- Prosthesis.

\section{B) Extra-oral examination}

- Patients were asked to open and close their mouth to diagnose the presence of clicking, deviation or any sound.

- Palpation of the TMJ area in both static and motion states to examine the tenderness or stiffness of the joints.

\section{Radiographic examination}

Radiological investigations using orthopantomogram(OPG) (opened \& closed) to assess the joint position in relation to the articular eminence.

Magnetic resonance imaging (MRI) was used to diagnose joint condition, disc shape and position, and disc - condyle relationship.

The disc-condyle relationship of the TMJ at maximum inter-occlusal position is considered optimal if the posterior band of the articular disc is directly above the mandibular condyle (i.e. 12 o'clock position) and the intermediate zone is interposed between the head of the mandibular condyle and the posterior slope of the articular eminence of the temporal bone.

\section{Operative phase}

1. Electromyography study and botulinum toxin type A injection via intraoral approach (Group $A)$ :
A) Botulinum toxin type A preparation

- Botulinum toxin type A(BTX-A) was reconstituted with sterile sodium chloride $9 \mathrm{mg} / \mathrm{ml}(0.9 \%)$ solution for injection; $2 \mathrm{ml}$ of sodium chloride solution was injected into the vial through the rubber cap and was gently mixed with BTX-A by moving vial side to side or rotating the vial gently.

- Shaken for one minute to ensure that all the powder was dissolved in the solution to be a clear colorless solution free of particles.

- $0.7 \mathrm{ml}$ of Botulinum toxin type $\mathrm{A}\left(\right.$ Botox $\left.^{\circledR}\right)$ was aspirated by an insulin syringe which contains to 35 units of Botox ${ }^{\circledR}$.

B) Needle insertion

The area of injection posterior to the maxillary tuberosity was disinfected by $10 \%$ povidone-iodine $10 \%$ (Betadine, The Nile Company for

Pharmaceutical and Chemical industries).

- Anesthesia of the disinfested area was done using topical lidocaine 10\% spray (Lidocaine, The Arab Drug Co.).

- The needle ran parallel to the maxillary alveolar ridge and posterior to the maxillary tuberosity in the lateral direction. It was inserted through the mucosa adjacent to the distal root of the maxillary second molar.

- Surface adhesive electrodes (Ground electrodes) were placed on the skin of the submental area of the patient, while in sitting position, and were connected with the EMG device.

- The patient was asked to protrude the mandible while the activity of the muscle was recorded with the EMG device to make sure that the needle was in the LPM.

\section{C) Electromyographic (EMG) recording}

Muscular activity of the LPM was measured using the EMG device and the following were recorded :

- The activity at rest: To detect abnormal rest potentials consistent with denervation.

- Activity during moderate contraction: To record motor unit action potentials.

- During maximum contraction: To record interference pattern.

D) Botox injection (Fig.3)

- The syringe containing 35 units of the Botox ${ }^{\circledR}$ solution was adapted to the needle and slowly injected into the muscle.

- After injection of the solution, the needle was withdrawn slowly from the muscle. Showing botulinum 
toxin injection via Intraoral route. Guided by electromyogophy.

2. Group B: IMF for 3 weeks (figure.4)

- Disinfection of the oral cavity.

- Local anesthesia.

- Upper and lower eyelets (4 eyelets).

- Inter maxillary fixation for 3 weeks.

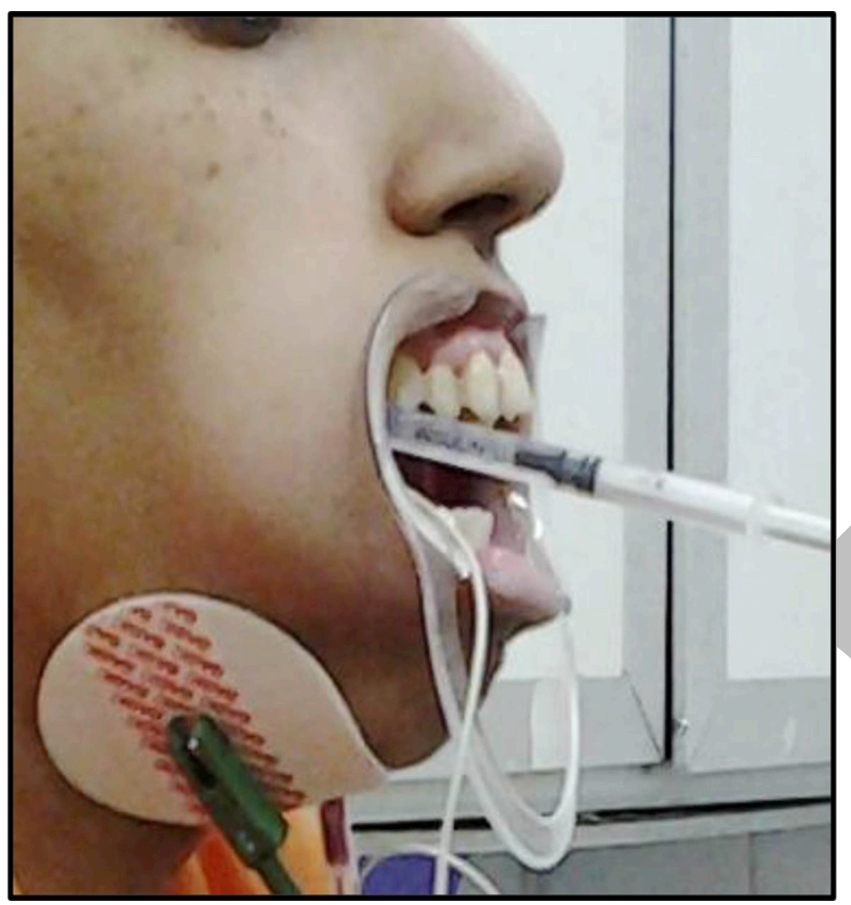

Fig. 3: Showing botulinum toxin injection via Intraoral route guided by electromyogophy.

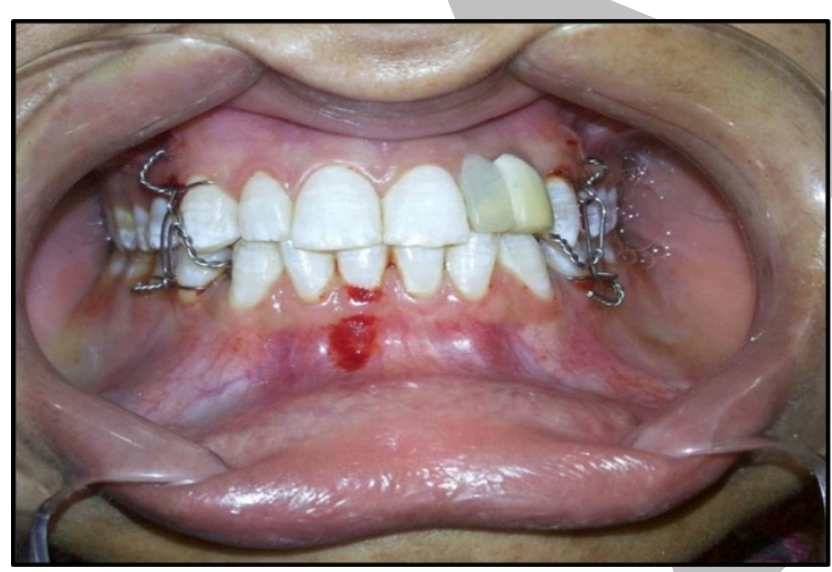

Fig. 4: Intermaxillary fixation.

\section{Post-operative phase}

Postoperative instructions

The patients were instructed to follow the conservative measurements of TMJ dislocation which were; soft diet, supporting the mandible while yawning, avoid cutting with the anterior incisors, and avoid chewing gum and hard objects for 10-14 days after injection because BTX-A injection does not seem to have an immediate effect.

\section{Follow up phase}

Follow up was done both clinically and radiographically.

1-Clinical follow up

Follow up was performed after 1 week, 3 months and 6 months. The outcome measurements were done by recording the occurrence of dislocations before and during therapy as well as the side effects that were recorded from the patients using a luxation protocol which include the following outcome measures:

- Frequency of dislocations after treatment.

- The severity of pain on the visual analogue scale (VAS).

- Maximum mouth opening.

- The muscular activity of the LPM was measured using electromyography (EMG).

\section{2-Radiographic follow up}

O.P.G (open \& closed) to assess the joint position in relation to the articular eminence.

MRI to study:

- The LPM and the condyle-disc

relationship.

- $\quad$ The LPM size and the presence of any

hypertrophy.

The size, shape and position of the disc.

The presence or absence of dislocation.

\section{Statistical analysis of the data}

The data were analyzed using IBM SPSS software package version 20.0. Quantitative data were described using range (minimum and maximum), mean, standard deviation and median. The Wilcoxon rank sum test was used to assess the significance of difference among the groups .Probabilities of $<0.05$ were accepted as significant.

\section{RESULTS}

One adverse reaction to the injection of BTA in the LPM was registered in the form of nasal regurgitation and nasal speech of one week's duration.

\section{I.Frequency of dislocation}

Eight patients from group A were diagnosed with bilateral recurrent TMJ dislocation and two with unilateral dislocation. Injections of BTX-A 35 units/muscle at the lower head of LPM were given guided by EMG. All treatments were successful, and there were no recurrences and no need for further injection during follow-up of 6 months.

While in the second group ten patients were treated by IMF for 3 weeks. Recurrence occurred in two of them after one week of treatment while the remaining patients did not show any signs of recurrence after giving them the instructions.

II. Maximum mouth opening assessment (Table 1) (Fig.5) Statistical analysis showed an obvious decrease in mouth opening from the pre to the postoperative treatment. The significant improvement in the mouth opening began 
after 1 week following the treatment in the two groups. The decrease in mouth opening continued thereafter and patients were able to open their jaws less than preoperative as time progressed especially in the first group. Prior to the injection treatment, the maximum mouth opening of the patients ranged between 45.0 and $58.0 \mathrm{~mm}$ with a mean of $50.70 \pm 4.35$. On $1^{\text {st }}$ week post-injection the mouth opening decreased to range between 39.0 and $53.0 \mathrm{~mm}$ with a mean of $45.40 \pm 4.38$. The maximum mouth opening continued to decrease reaching between 35.0 and $46.0 \mathrm{~mm}$ with a mean of $40.30 \pm 3.92$ on the $3^{\text {rd }}$ month. Six months after the injection, improvement continued to be noticed; the maximum mouth opening of the injected patients reached a range between 33.0 and $44.0 \mathrm{~mm}$ with a mean of $36.30 \pm$ 3.40 .

While in the control group the maximum mouth opening showed limitations near to the study group ranging between 40.0 and $54.0 \mathrm{~mm}$ with a mean of $47.20 \pm 4.34$ after preoperative mouth opening ranging between 45.0 and 58.0 $\mathrm{mm}$ with mean of $50.70 \pm 4.22$. Then the mouth opening started to increase again ranging between 42.0 and $55.0 \mathrm{~mm}$ on the $3^{\text {rd }}$ month postoperative. Six months after treatment the mouth opening continued to increase reaching a range between 43.0 and $56.6 \mathrm{~mm}$ with a mean of $49.40 \pm 4.30$.

Table 1: Comparison between the two studied groups according to mouth opening.

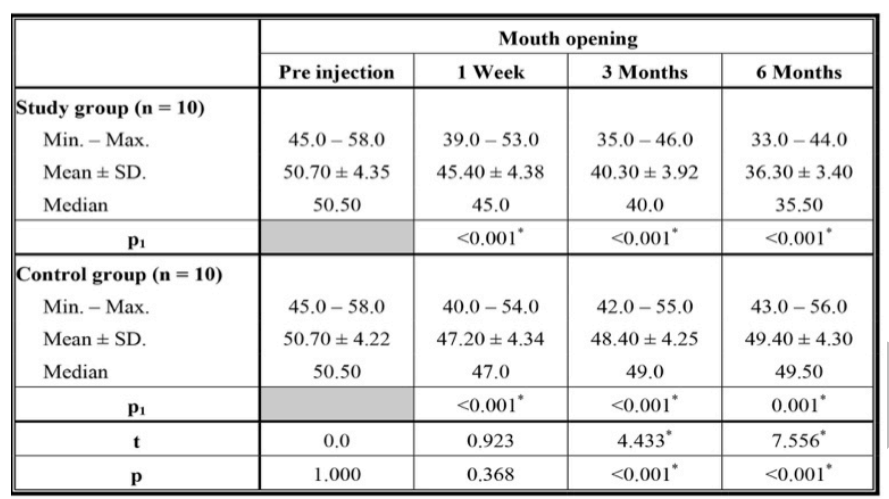

$\mathrm{p}_{1}: \mathrm{p}$ value for Post Hoc Test (LSD) for F test (ANOVA) with repeated measures for comparison between Pre injection with each other period

t: Student t-test

*: Statistically significant at $\mathrm{p} \leq 0.05$

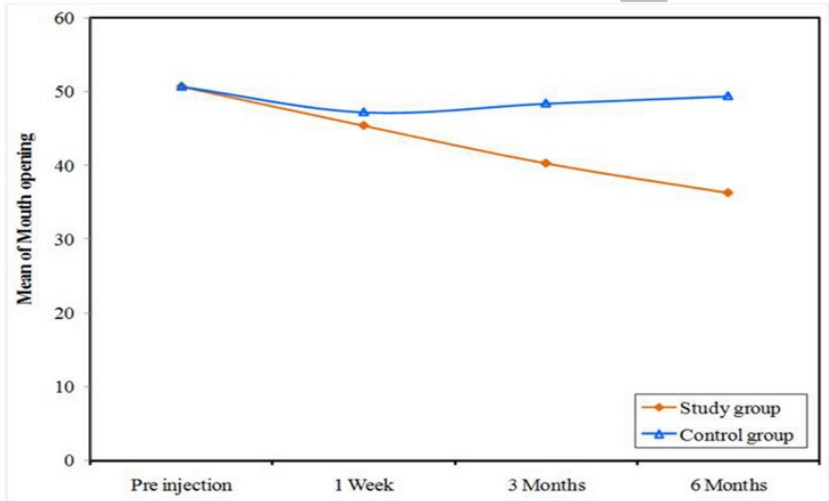

Fig. 5: Comparison between the two studied groups according to mouth opening.

Alexandria Dental Journal. (2015) Vol.40 Pages:200-207
III. Visual Analogue Scale (VAS) (Table 2)(Fig.6)

Statistical analysis showed an initial decrease in the pain level from the pre injection to the post-injection treatment. The obvious improvement in the pain level occurred after 1 week of the injection. The pain level continued to improve thereafter. The pain score before the injection ranged between 7.0 and 10.0 with a mean of 8.70 \pm 0.95 . On the 7 th day post-injection the pain level decreased to 5.0 and 9.0 with a mean of $6.0 \pm 1.25$. It continued to decrease reaching 1.0 and 5.0 with a mean of $2.50 \pm 1.27$ on the $3^{\text {rd }}$ month, Six months post-injection, the pain scale was 0.0 and 3.0 with a mean of $0.50 \pm 0.97$.

While in the control group statistical analysis showed an initial decrease in the pain level from the preoperative to the postoperative treatment. The most significant improvement in the pain level occurred after 1 week of the inter-maxillary fixation release. The pain score before the IMF ranged between 7.0 and 10.0 with a mean of $8.20 \pm 1.03$. On the 7 th day post-injection the pain level decreased to 6.0 and 8.0 with a mean of $6.50 \pm .71$. Again the pain started to increase reaching 5.0 and 9.0 with a mean $6.70 \pm 1.16$ on the $3^{\text {rd }}$ month, Six months postoperative, the pain scale was 5.0 and 9.0 with a mean of $7.20 \pm 1.932$.

Table 2: Comparison between the two studied groups according to Visual analogue Scale (VAS).

\begin{tabular}{|c|c|c|c|c|}
\hline & \multicolumn{4}{|c|}{ Visual analogue Scale (VAS) } \\
\hline & Pre injection & 1 Week & 3 Months & 6 Months \\
\hline \multicolumn{5}{|c|}{ Study group $(\mathrm{n}=10)$} \\
\hline Min. - Max. & $7.0-10.0$ & $5.0-9.0$ & $1.0-5.0$ & $0.0-3.0$ \\
\hline Mean \pm SD. & $8.70 \pm 0.95$ & $6.0 \pm 1.25$ & $2.50 \pm 1.27$ & $0.50 \pm 0.97$ \\
\hline Median & 9.0 & 6.0 & 2.0 & 0.0 \\
\hline $\mathbf{p}_{1}$ & & $0.005^{*}$ & $0.004^{*}$ & $0.004^{*}$ \\
\hline \multicolumn{5}{|c|}{ Control group $(n=10)$} \\
\hline Min. - Max. & $7.0-10.0$ & $6.0-8.0$ & $5.0-9.0$ & $5.0-9.0$ \\
\hline Mean $\pm \mathrm{SD}$ & $8.20 \pm 1.03$ & $6.50 \pm 0.71$ & $6.70 \pm 1.16$ & $7.20 \pm 1.32$ \\
\hline Median & 8.0 & 6.0 & 6.50 & 7.0 \\
\hline $\mathrm{p}_{1}$ & & $0.004^{*}$ & $0.007^{*}$ & $0.008^{*}$ \\
\hline $\mathbf{z}$ & 1.103 & 1.670 & $3.780^{\circ}$ & $3.874^{\circ}$ \\
\hline $\mathbf{p}$ & 0.270 & 0.095 & $<0.001^{\circ}$ & $<0.001^{\circ}$ \\
\hline
\end{tabular}

$p_{1}: p$ value for Wilcoxon signed ranks test for comparison between Pre injection with each other period

*: Statistically significant at $\mathrm{p} \leq 0.05$

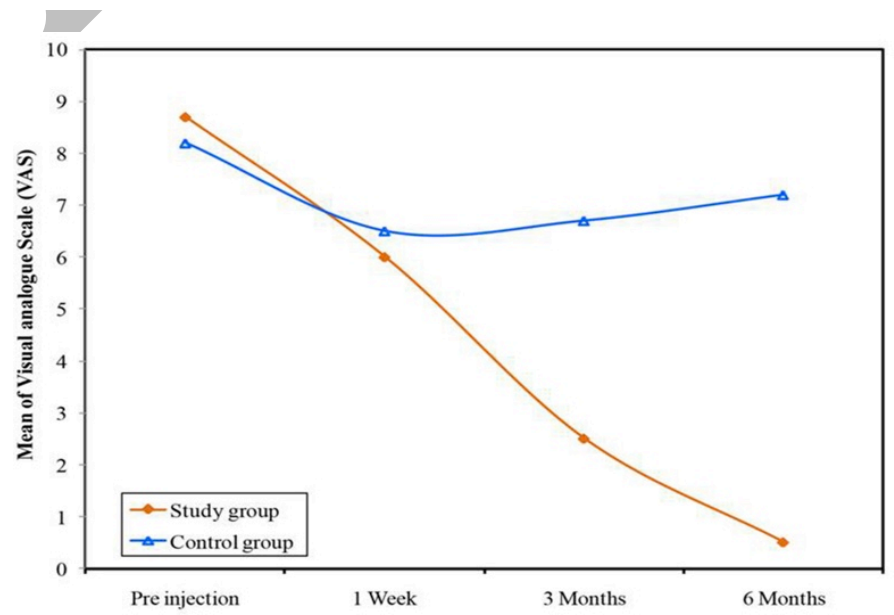

Fig. 6: Comparison between the two studied groups according to Visual analogue Scale (VAS). 


\section{Muscle activity Assessment using EMG in group A}

Data collected from EMG test prior to the injection (base line evaluation) showed that while at rest, the muscle was electrically silent with no evidence of denervation. The motor unit action potentials (MUAP) recorded during moderate contraction were either biphasic or triphasic with normal amplitude and duration, while during maximum contraction there was complete interference pattern.

During the $1^{\text {st }}$ week after the injection, EMG test showed evidence of acute (early) neuropathy; there was evidence of abnormal rest potentials (fibrillation potentials and/ or positive shape waves) consistent with denervation, while during moderate contractions the MUAP were of normal morphology with dropout of motor units. The maximum contraction showed incomplete interference pattern.

Three to four months after the injection, the EMG test revealed results of early re-innervation; at rest, there was no evidence of abnormal rest potentials. The MUAP were small polyphasic units consistent with regeneration recorded during moderate contractions, while incomplete interference pattern during maximum contraction.

\section{Temporomandibular joint assessment using OPG} Images of both TMJ at the end of the study showed no changes from those taken prior to the injection. Images taken before and after the injection showed normality of the TMJ bony components. There was also no evidence of bony changes of the condyle, fossa, and temporal eminence. It is also worth mentioning that there was no evidence of secondary bony changes from images taken at the end of 6 months in both groups.

\section{Muscle activities Assessment using (MRI)}

Reports from MRI images of the TMJ at the end of the study showed no changes from those taken prior to the injection. Images taken before and after the injection showed normality of the LPM. There was also no evidence of muscle fatty atrophy or hypertrophy.

MRI images were also taken of the disc from the TMJ view 6 months post-injection, the disc showed normal size, and shape. In addition normal anterior translation of the condyle- meniscal complex was reported in open mouth position. It is also worth mentioning that there was no evidence of secondary bone changes or soft tissue masses from images taken at the end of 6 months after the injection

\section{DISCUSSION}

Since Botulinum Toxin type A discovery in 1897 to its introduction as a therapeutic agent in 1977 to present day, BTX-A has evolved from a poison to a versatile clinical tool with an expanding list of uses. It is very useful in the treatment of a broad array of disorders resulting from muscular hyperfunction and, more recently, autonomic dysfunction. There have been several anecdotal reports of the use of BTX-A as treatment for TMJ dislocation (13-15).

As a result, based on previous opinions of clinical trials on the effectiveness of using BTX-A to treat temporomandibular joint disorders (TMD), twenty patients, suffering from chronic recurrent TMJ dislocation were selected from the Oral and Maxillofacial Surgery Department of the Faculty of Dentistry, Alexandria University. The selected patients did not respond to conservative therapy.

BTA is a powerful neurotoxin selectively taken up by cholinergic nerve terminals, where it prevents the release of acetylcholine by damaging a protein needed to fuse vesicles with the cell membrane (SNAP-25). The response to BTA is influenced by the dosage (dose-dependent effect), the injection technique, and the size (mass) of the injected muscle. Dose selection is still empirical, and the lowest effective dose is recommended $(16,17)$.

The lateral pterygoid muscle was injected with $35 \mathrm{IU}$ of Botox ${ }^{\circledR}$ which is the reasonable therapeutic dose for LPM. As, the LPM is a small and deep muscle which makes it difficult to locate, EMG was used for guidance during the injection of BTX-A (18,20-23). It is safely introduced into the LPM to measure the activity of the affected muscle before and after the injection treatment.

Preoperative MRI was performed to evaluate the TMJ, soft tissue, the disc- condyle relationship and for determination of disc displacement. In pre-injection MRI evaluation, there was no articular cartilage degeneration, disc displacement, or osteoarthritis in any patients before administration of the injection.

The lateral pterygoid muscle plays an important role in TMD. Stable and reliable methods to evaluate the LPM are still lacking. MRI has been confirmed as an important tool in diagnosing muscular diseases. Yang (2002) (19), reported that the MRI was used in imaging diagnosis of the LPM with the aim of detecting pathological changes of the LPM in patients with TMD.

The use of panoramic radiography imaging exam for diagnostic prediction in clinical practice did not seem advisable. These findings are compatible with previous studies that have sought a correlation between the signs and symptoms of TMD and imaging findings (24).

The effect of BTX-A started 7 days after injection and the effect lasted for more than 6 months. The denervation of muscle was noted; the dystonia of the muscle at rest position decreased as a result of chemical denervation, and the BTX-A injection led to the direct attenuation of these muscle contractions. In addition, the chemical denervation at the neuromuscular end plate induced inactivity atrophy in the region of the effected muscle (25).

Three to months after the injection, re-innervation of the muscle started indicating cessation of the chemical effect of the Botox ${ }^{\circledR}$. Examination of the muscle was important at this point; if the muscle dystonia and the symptoms were back again, it would indicate that the clinical effectiveness of BTX-A ended six months following the injection and reinjection of the muscle is required.

This was in accordance with Korean (2012) (26), who reported that The effect of botulinum toxin type $A$ is typically seen few days after the injections, and it can last for several months before the injections need to be repeated.

In addition, Colhado et al (2009) (27), stated that the onset of action of Botulinum Toxin on the skeletal muscle 
takes a few days ( 2 to 5 days), but occasionally it can take up to two to three weeks. Once instituted, the effects last from six weeks to six months (a mean of three to four months), in a study to evaluate the effect of BTX-A in the treatment of pain.

Moreover, in a study performed by Borodic and Acquadro (2002) (28), reported that the duration of beneficial effect of BTX-A ranged from 2 to 4 months.

Furthermore, Von Lindern (2001) (29), stated that the LPM does not regain its original degree of hyperactivity and may indeed undergo involution following Botox ${ }^{\circledR}$ injection. They also concluded that BTX-A treatment is a temporary treatment, it has proven to be the most effective treatment of choice among study cases. Patients who required repeated injections, remained symptom free for over six months after the injection treatment.

Botulinum Toxin type A produced a significant improvement in the pain level. Actually, the responses varied from partial relief of pain to complete pain relief. According to the VAS recorded by the patients, the pain started with a mean of 10.0 and dropped to 0.0 after 6 months following injection. While in the other group there was insignificant pain improvement.

This is in agreement with Girdler (1994) (30), Von Lindern (2001) (29), and Kandil (2013) (31) who found that $90 \%$ of patients showed an overall improvement in pain following injection of BTX-A.

The maximum mouth opening and jaw functions of all the patients from Group A and Group B were measured. Subsequently, the results were assessed before the injection treatment and over a period of 6 months after the treatment. The maximum mouth opening before the injection had a mean of $50.70 \mathrm{~mm}$ and after six months it decreased to reach a mean of $36.30 \mathrm{~mm}$. While in the $2^{\text {nd }}$ group the regarding mouth opening measurements.

It was believed that the procedure was well tolerated and, in general, no anesthesia was needed. The effects were typically seen within 3 to 10 days after the injection, and they generally lasted 3 to 6 months $(30,32)$. The muscle recovers over several months as the nerve terminal regenerates new protein. The permanent clinical response obtained in the patients may be due to permanent weakening of the muscles or to fibrosis generated around the joint after movement restriction $(33,34)$.

It was registered that only one adverse reaction to the injection of BTA in the external pterygoid muscle which was transient nasal regurgitation and nasal speech of one week's duration, possibly due to diffusion of the drug into adjacent muscles. The literature records transient dysphagia in $8 \%$ of the patients treated as the most frequent complication. Rarer adverse defects are nasal speech, painful chewing, nasal regurgitation, and dysarthria $(17,19,24,26)$. All adverse reactions subside within 2 to 4 weeks. In rare cases, patients may develop antibodies to BTX-A; this occurs more often with BTX-A injections of doses higher than 200 U, with intervals between procedures of one month or less, and with accidental intravenous injections (35). This can result in clinical resistance to subsequent injections.

Botulinum toxin type A is established as a treatment of choice for focal dystonias and other conditions with focal involuntary muscle activity $(36,37)$. These results correspond with the literature which suggested that BTA might become a valuable treatment in recurrent dislocation of the TMJ. There are various surgical options for successfully managing recurrent dislocation of the TMJ if conservative measures fail. Although BTA injection was invasive, it was a relatively conservative option. It was considered as an initial approach in all cases, because LPM was straightforward and can performed in outpatients with little risks.

Immobilization of the mandible by maxillomandibular fixation has been used, but have failed to achieve permanent, satisfactory results. It is also difficult for such patients to comply with the treatment.

These results correspond with Shorey and Campbell (2000) (3), who stated that Immobilization of the mandible by maxillomandibular fixation and active physiotherapy have been used alone or with other treatments, but have failed to achieve permanent, satisfactory results. It is also difficult for such patients to comply with the treatment.

\section{CONCLUSIONS}

1-Botolinum Toxin type A is effective in treatment of temporomandibular joint dislocation and in reducing pain resulting from the excessive movement of the LPM.

2-The effectiveness of BTX-A is temporary but may extend over a period of time. Injection may be repeated in case of recurrent dislocation.

3-BTX-A injection is invasive, but is a relatively conservative option because it is a safe and effective treatment for dystonia.

4-It can be used as an initial approach because injection into the LPM is straightforward and can be done in outpatients with few complications.

\section{CONFLICT OF INTEREST}

The authors declare that they have no conflict of interest.

\section{REFERENCES}

1. Undt G, Kermer C, Piehslinger E, Rasse M. Treatment of recurrent mandibular dislocation. Part I. Leclerc blocking procedure. Int J Oral Maxillofac Surg 1997; 26: 92-7.

2. Hale RH. Treatment of recurrent dislocation of the mandible: review of literature and report of cases. J Oral Surg 1972; 30: 527-30.

3. Shorey C, Campbell J. Dislocation of the temporomandibular joint. Oral Surg Oral Med Oral Pathol Oral Radiol Endod 2000; 89: 662-8.

4. Thangarajah T, McCulloch N, Thangarajah S, Stocker J. Bilateral tempromandibular joint dislocation in a 29year-old man: a case report. J Med Case Rep 2010; 4: 263.

5. Akinbami BO. Evaluation of the mechanism and principles of management of temporomandibular joint dislocation. Systematic review of literature and a 
proposed new classification of temporomandibular joint dislocation. Head Face Med 2011; 7: 10.

6. Medra AM, Mahrous AM. Glenotemporal osteotomy and bone grafting in the management of chronic recurrent dislocation and hypermobility of the temporomandibular joint. Br J Oral Maxillofac Surg 2008; 46: 119-22.

7. Kummoona R. Surgical reconstruction of the temporomandibular joint for chronic subluxation and dislocation. Int J Oral Maxillofac Surg 2001; 30: 344-8.

8. Lovely FW, Copeland RA. Reduction eminoplasty for chronic recurrent luxation of the temporomandibular joint. J Can Dent Assoc 1981; 3: 179-84.

9. Daif E. Autologous blood injection as a new treatment modality for chronic recurrent temporomandibular joint dislocation. Oral Surg Oral Med Oral Pathol Oral Radiol Endod 2010; 109: 31-6.

10. Leopard PJ. Surgery of the non-ankylosed temporomandibular joint. Br J Oral Maxillofac Surg 1987; 25: 138-48.

11. Sinclair CF, Gurey LE, Blitzer A. Oromandibular dystonia: long-term management with botulinum toxin. Laryngoscope 2013; 123: 307883.

12. Martínez-Pérez D, García Ruiz-Espiga P. Recurrent temporomandibular joint dislocation treated with botulinum toxin: report of 3 cases. J Oral Maxillofac Surg 2004; 62: 244-6.

13. Moore AP, Wood GD. Medical treatment of recurrent temporomanibular joint dislocation using botulinum toxin A. Dent J 1997; 23: 127-32.

14. Daelen B, Thorwirth V, Koch A. Treatment of recurrent dislocation of the temporomandibular joint with type A botulinum toxin. Int J Oral Maxillofac Surg 1997; 26: 458.

15. Freund B, Schwartz M, Symington JM. Botulinum toxin: new treatment for temporomandibular disorders. Br J Oral Maxillofac Surg 2000; 38: 466-71.

16. Hambleton P, Moore AP. Botulinum neurotoxins: Origin, structure, molecular actions and antibodies. In: Moore AP (ed). Handbook of Botulinim Toxin Treatment. Oxford, England: Blackwell Scientific, 1995. 16-27.

17. Brin MF. Botulinum toxin therapy: Basic sciences and overview of other therapeutic applications. In: Blitzer A, Binder WJ, Boyd JB (eds). Management of Facial Lines and Wrinkles. Philadelphia, PA: Lippincott Williams and Wilkins, 1999. 279-302.

18. Jost WH. Botulinum Toxin in Painful Diseases, Pain Headache. Vol 14. Basel: Karger, 2003. 82-101.

19. Yang X, Pernu H, Pyhtinen J, Tiilikainen PA, Oikarinen KS, Raustia AM. MRI abnormalities of the lateral pterygoid muscle in patients with non-reducing disk displacement of the TMJ. Cranio 2002; 20: 209-21.

20. Christoph M, Ziegler CM, Haag C, Muhling J. Treatment of recurrent temporomandibular dislocation with intramuscular botulinum toxin injection. Clin Oral Invest 2003; 7: 52-5.
21. Marvin S. Treatment of the temporomandibular disorder with botulinum toxin. Clin J Pain 2002; 18: 198-203.

22. Brin MF, Fahn S, Moskowitz C, Friedman A, Shale $\mathrm{HM}$, Greene PE, et al. Localized injections of botulinum toxin for the treatment of focal dystonias and hemifacial spasm. Mov Disord 1987; 2: 237.

23. Brin MF, Blitzer A, Herman S. Orofaciomandibular and lingual dystonia. In: Moore AP (eds). Handbook of Botulinim Toxin Treatment. Oxford, England: Blackwell Scientific, 1995. 151-63.

24. Bertram S, Rudisch A, Innerhofer K, Pümpel E, Grubwieser G, Emshoff R. Diagnosing TMJ internal derangement and osteoarthritis with magnetic resonance imaging. J Am Dent Assoc 2001; 132: 753-61.

25. Zuber M, Sebald M, Bathien N, de Recondo J, Rondot P. Botulinum antibodies in dystonic patients treated with type A botulinum toxin. Frequency and significance. Neurology 1993; 43: 1715-8.

26. Korean J. Oromandibular dystonia after dental treatment. Assoc Oral Maxillofac Surg 2012; 38: 379-83.

27. Colhado O, Boeing M, Borina L. Botulinum toxin in pain treatment. Rev Bras Anestesiol 2009; 59: 366-81.

28. Borodic GE, Acquadro MA. The use of botulinum toxin for treatment of chronic facial pain. J Pain 2002; 3: 21-7.

29. Von Lindern JJ. Type Abotulinum toxin in the treatment of chronic facial pain associated with temporo-mandibular dysfunction. Acta Neural Belg 2001; 101: 39-41.

30. Girdler M. Use of botulinum toxin to alleviate facial pain. Br J Hosp Med 1994; 52: 363.

31. Kandil M. The effect of botulinum toxin (botox) on persistent painful tempromandibular joint. Thesis Oral and Maxillofacial Surgery. Faculty of Dentistry. Alexandria University. Egypt. 2013. 40-3.

32. Dijkgraaf LC, de Bont LG, Boering G, Liem RS. Structure of the normal synovial membrane of the temporomandibular joint: a review of the literature. $\mathrm{J}$ Oral Maxillofac Surg 1996; 54: 332-8.

33. De leeuwr, Boering G, Stegena B, Bont LG. Radiographic signs of temporomandibular joint osteoarthritis and internal derangement. Oral Surg Oral Med Oral Path Oral Radiol 1995; 79: 382-93.

34. Sato S, Takahashi K, Kawamura H, Moteegi K. The natural course of non reducing disc displacement of the temporomandibular joint. Int $\mathrm{J}$ Oral Maxillofac Surg 1998; 27: 173-8.

35. Okeson JP. Bell's orofacial pains: The clinical management of orofacial pain. $6^{\text {th }}$ ed. New Malden, Surrey, UK: Quintessence Publishing Co. Ltd, 2005. 567.

36. Carruthers A, Kiene K, Carruthers J. Botulinum toxin A exotoxin use in clinical dermatology. J Am Acad Dermatol 1996; 34: 788.

37. Undt G, Weichselbraun A, Wagner A, Kermer C, Rasse M. Recurrent mandibular dislocation under neuroleptic drug therapy treated by bilateral eminectomy. J Craniomaxillofac Surg 1996; 20: 217. 